\title{
Chaetotaxy of three nymphal instars of an ischnoceran louse, Aegypoecus perspicuus (Phthiraptera: Insecta)
}

\section{G. P. Agarwall ${ }^{1}$,Aftab A hmad², Gaurav Arya ${ }^{2}$, Renu Saxena ${ }^{3}$, Arjumand Nisar $^{2}$ and A. K . Saxena2*}

${ }^{1}$ Ex-Head, Department of Zoology, Banaras Hindu University, Banaras, (U.P.), INDIA

Present Address:168, Deshbandhu Apartments, Kalka ji, New Delhi, INDIA

${ }^{2}$ Department of Zoology, Govt. Raza P. G. College, Rampur ( U.P.), INDIA

${ }^{3}$ Department of Zoology, B.S.A. College, Mathura (U.P.), INDIA

*Correspondence author. E-mail: akscsir@ rediffmail.com

Abstract: The present study on three nymphal instars of Aegypoecus perspicuus indicated that these differ from each other not only an size, abdominal segmentation, chitinization but also in the number of setae occurring on head, thorax and abdomen. The study also supplements informations regarding the morphological features and chaetotaxy of three nymphal instars of A. perspicuus, occurring on Neophron percnopterus. The diagnostic features of three nymphal instars have also been discussed.

Keywords: Aegypoecus, Chaetotaxy, Chewing lice, Ischnocera, Phthiraptera

\section{INTRODUCTION}

Three nymphal instars of avian Phthiraptera resemble to each other to a considerable extent (except the size). Hence, the differentiation between the instars is a challenging task. Few workers have casually discussed the morphological features of the nymphal instars of certain species while describing their biology. However, Clay (1958), Modrejewska and Zlotorzycka (1987) and Mey (1994) have made specific attempts to provide information on the nymphal chaetotaxy of few avian lice. Since then, few more phthirapterists (Lonc and Modrezweska, 1986, 1989; Page et al., 1995; Price and Hallenthal, 1996; Saxena etal., 1998 and 2000; Smith, 2000; Cicchino and Castro, 2002 and Slike et al., 2006) have provided further information on the nymphal chaetotaxy. Present paper provides supplements regarding the chaetotaxy of three nymphal instars of Aegypoecus perspicuus, occurring on Neophron percnopterus.

\section{MATERIALS AND METHODS}

Nymphal instars of A. perspicuus were treated with $20 \%$ $\mathrm{KOH}$ " 24 hrs", washed thrice (in water), passed through $10 \%$ acetic acid, dehydrated (ethanol series), cleared (clove oil) and mounted (Canada Balsom) and subjected to microscopy.

\section{RESULTS}

First instar nymph (Tables 1 and 2, Figs. 1 and 4): The first instar nymph is opaque white in colour and measures $1.1 \mathrm{~mm}$ in length and $0.6 \mathrm{~mm}$ in breadth. It possesses a prominent head, a short thorax and a relatively small abdomen. The head is broader than long, somewhat triangular in shape, and its lateral margins are more rounded than in the succeeding instars. The pre-antennal region is shorter than the post- antennal region and is slightly concave at its anterior end. The small coni hardly project beyond the lateral margins. The post- antennal region is wider behind the eyes, but is rounded along the temporal margins. Each eye is provided with an ocular seta. The antennae are filiform, five segmented, in which the proximal segments are longer than the others. The cutting edges of the mandibles are brown and pigmented. Hypopharynx is poorly developed, and only a faint gular plate is distinguishable. The arrangement of setae on the head corresponds to that in the adult but the setae are comparatively longer.

The thorax is smaller than the head, both in length and breadth (Fig. 1). The pro- thorax is slightly smaller than the ptero- thorax and its posterior margin is almost straight, while the posterior margin of pterothorax is slightly concave. The legs consist of the three usual parts and are well developed, the first pair is smaller than the others.

The rounded abdomen is slightly smaller than the head (Figs1 and 3). The abdomen appears to consist of ten segments only because the original eleven segmental conditions have been reduced to this number as a result of the fusion of segments I and II. Segmentation on the dorsal side is visible up to segment VIII, but the suture is present laterally only. There is no sign of segmentation between segments IX and X but there is clear indication of a terminal segment which has been interpreted as ISSN : 0974-9411 (Print), 2231-5209 (Online) All Rights Reserved ๑ Applied and Natural Science Foundation www.ansfoundation.org 
Table 1. Showing measurements of first, second and third instars of A. perspicuus.

\begin{tabular}{|c|c|c|c|c|c|c|}
\hline & \multicolumn{2}{|c|}{ First instar } & \multicolumn{2}{|c|}{ Second instar } & \multicolumn{2}{|c|}{ Third instar } \\
\hline & L ength & width & Length & width & Length & width \\
\hline \multirow{2}{*}{ Head } & 0.45 & 0.59 & 0.54 & 0.65 & 0.69 & 0.79 \\
\hline & $(0.40-0.48)$ & $(0.54-0.61)$ & $(0.49-0.57)$ & $(0.59-0.69)$ & $(0.60-0.71)$ & $(0.70-0.81)$ \\
\hline \multirow{2}{*}{ Thorax } & 0.20 & 0.41 & 0.26 & 0.54 & 0.39 & 0.63 \\
\hline & $(0.19-0.21)$ & $(0.40-0.42)$ & $(0.23-0.3)$ & $(0.5-0.55)$ & $(0.3-0.42)$ & $(0.55-0.68)$ \\
\hline \multirow{2}{*}{ Abdomen } & 0.44 & 0.50 & 0.65 & 0.77 & 0.83 & 1.05 \\
\hline & $(0.40-0.50)$ & $(0.48-0.52)$ & $(0.6-0.7)$ & $(0.65-0.79)$ & $(0.72-0.92)$ & $(0.90-1.09)$ \\
\hline \multirow{2}{*}{ Total } & 1.09 & 0.59 & 1.5 & 0.77 & 1.90 & 1.05 \\
\hline & $(0.96-1.20)$ & $(0.54-0.61)$ & $(1.25-1.60)$ & $(0.65-0.79)$ & $(1.7-2.0)$ & $(0.90-1.09)$ \\
\hline \multirow{2}{*}{ Antenna } & 0.19 & 0.032 & 0.21 & 0.038 & 0.23 & 0.042 \\
\hline & $(0.19-0.20)$ & $(0.03-0.034)$ & $(0.20-0.22)$ & $(0.03-0.039)$ & $(0.04-0.043)$ & $(0.04-0.043)$ \\
\hline C.I & \multicolumn{2}{|c|}{$0.13(0.127-0.135)$} & \multicolumn{2}{|c|}{$0.12(0.12-0.122)$} & \multicolumn{2}{|c|}{$0.115(0.114-0.127)$} \\
\hline
\end{tabular}

segment XI. Even tough there is no sign of segmentation between segments IX and $X$ yet they have not undergone fusion, as is their condition in the adult. This is shown by the appearance of the suture between segments IX and $\mathrm{X}$ in the second instar nymph it is confined to the lateral margins and is never too prominent. There is no indication of segmentation of the venter. The abdomen is widest at segments IV-V and converges posteriorly to form a rounded margin. The terminal segment (XI) is deeply emarginated posteriorly. A pair of spiracles is present laterally on segments III- VIII.

Second instar nymph(Tables 1 and 2, Figs 2 and 5): It differs from the first instar nymph in size, pigmentation, shape of head and shows marked increase in the size of the abdomen and the number of setae. It measured 1.5 $\mathrm{mm}$ in length and $0.8 \mathrm{~mm}$ in breadth.

The lateral margins of the head (Fig. 2) are straighter than in the previous instar with the result that it has become triangular in shape. The hypopharynx appears harder and darker and the gular plate is now visible due to slight pigmentation.
The thorax (Fig. 2) becomes more prominent and spiracles on each postero-lateral angle of the prothorax are discernible. The posterior margin of the pterothorax becomes more concave and medianly covers an appreciable part of abdominal segment II. The prothoracic chaetotaxy shows no change but in the pterothorax 2 setae are added on the dorso-lateral margin, each side and 1-2 setae on the posterior margin. A transversely articulating sclerite becomes visible between the coxae of the first and second pair of legs.

The abdomen shows greater increase in size in this instar (Figs. 2 and 5) than any part of the body, to become the most prominent part. The numbers of segments remain the same but the segmentation becomes clearly on the dorsal side and appears on ventral side as well. A trace of pigmentation appears on the lateral margins of segments II- III. Between segments IX and X a faint suture appears, on each side, showing that they are separate and have yet to undergo fusion. The chaetotaxy and the various measurements of the different parts of the body of second instar nymph are given in the Table 1 and 2.

Table 2. Showing chaetotaxy of first, second and third instars of A. perspicuus.

\begin{tabular}{|c|c|c|c|c|c|c|c|c|c|}
\hline \multirow{2}{*}{$\begin{array}{l}\text { Stage } \rightarrow \\
\text { Region } \downarrow\end{array}$} & \multicolumn{3}{|c|}{ First instar } & \multicolumn{3}{|c|}{ Second instar } & \multicolumn{3}{|c|}{ Third instar } \\
\hline & Tergal & Pleural & Sternal & Tergal & Pleural & Sternal & Tergal & Pleural & Sternal \\
\hline Prothorax & 1,1 & 0,0 & 0,0 & 1,1 & 0,0 & 0,0 & 1,1 & 0,0 & 0,0 \\
\hline Pter othorax & $1,3-4,1$ & 0,0 & 0,0 & $3,4-5,3$ & 0,0 & 0,0 & $3,7-8,3$ & 0,0 & 0,0 \\
\hline \multirow[t]{2}{*}{ II } & 2 & & & 2 & & & 2 & & \\
\hline & 2 & 0,0 & 2 & $8-9$ & 0,0 & 4 & $16-18$ & 0,0 & $8-9$ \\
\hline III & $1,4,1$ & & 2 & $8-10$ & 2,2 & $7-8$ & $18-20$ & 3,3 & $14-16$ \\
\hline IV & $1,4,1$ & & 2 & $8-10$ & 4,4 & $7-8$ & $16-18$ & $8-9,8-9$ & $14-16$ \\
\hline V & $1,4,1$ & 1,1 & $1,2,1$ & $6-7$ & 4,4 & $6-7$ & $16-17$ & $7-8,7-8$ & $12-13$ \\
\hline VI & $1,4,1$ & 1,1 & $1,2,1$ & $6-7$ & 4,4 & 2 & $11-13$ & $6-7,6-7$ & $12-13$ \\
\hline VII & $1,4,1$ & 1,1 & $1,2,1$ & $6-7$ & 4,4 & 2 & $7-8$ & $4-6,4-6$ & 2 \\
\hline VIII & $1,4,1$ & 1,1 & $1,2,1$ & $6-7$ & 4,4 & 2 & $6-7$ & 4,4 & 2 \\
\hline IX & 2 & 1,1 & 2 & 2 & 1,1 & $2,2,2$ & 0,0 & 1,1 & $3,2,3$ \\
\hline$X$ & 2 & 1,1 & 2 & 4 & 1,1 & & 4 & 1,1 & \\
\hline XI & 0,0 & 0,0 & 0,0 & 0,0 & 0,0 & 0,0 & 0,0 & 0,0 & 0,0 \\
\hline
\end{tabular}


(1)

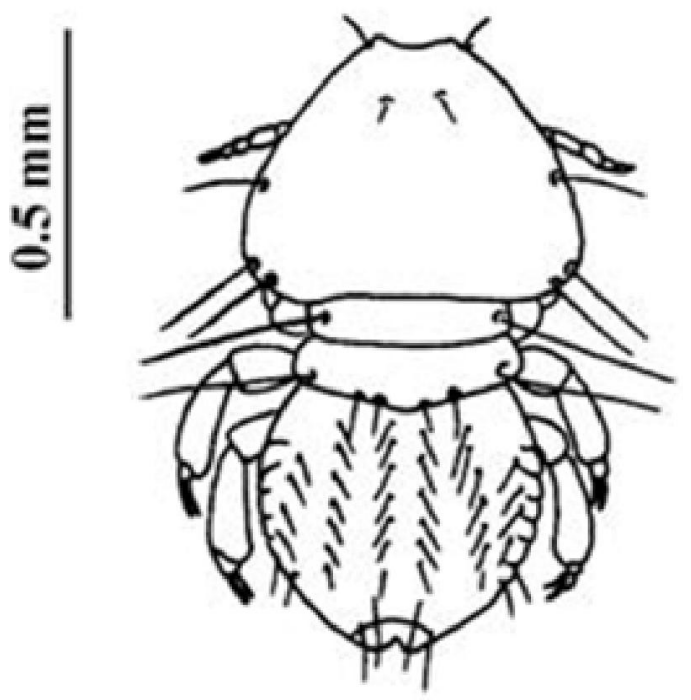

(3)

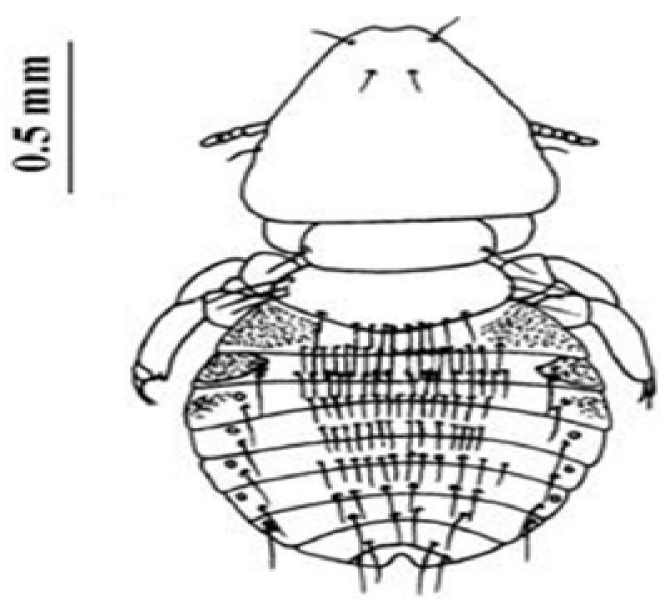

(5)

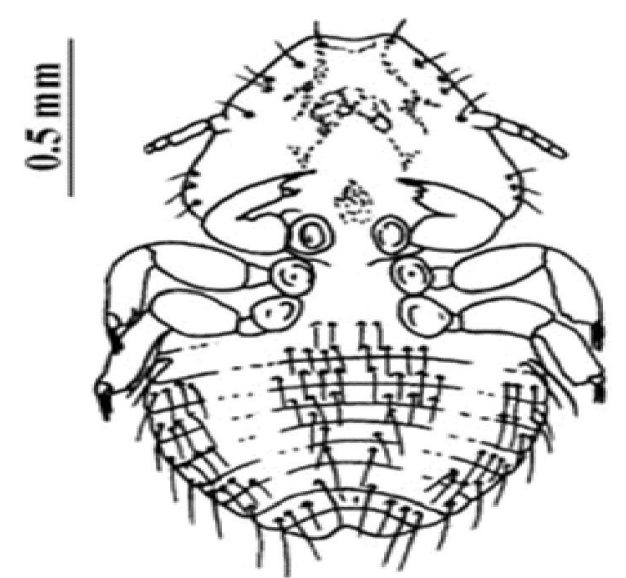

(2)

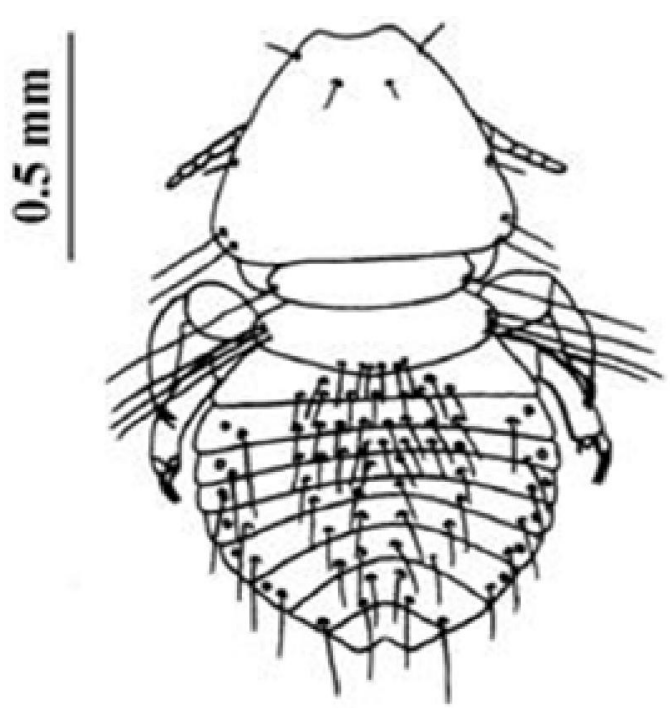

(4)

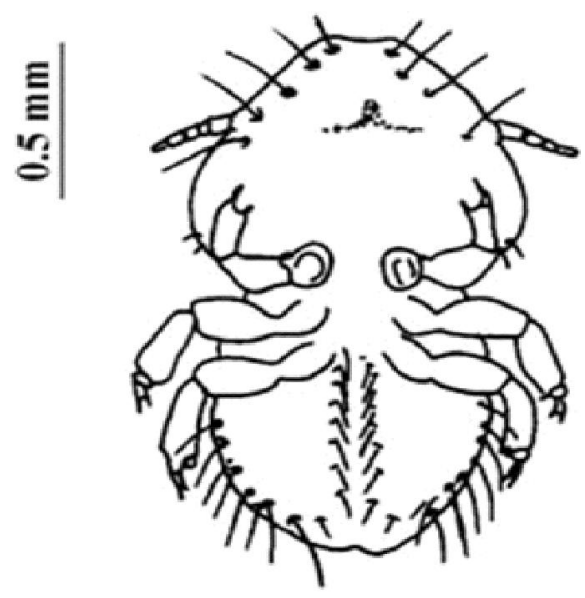

(6)

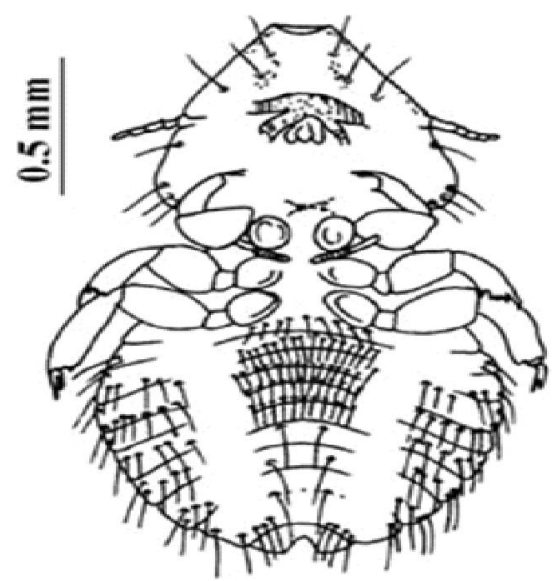

Figs. 1-3. D orsal aspect of A. perspicuus: (1). First instar nymph, (2). Second instar nymph, (3). Third instar nymph.4-6. Ventral aspect of $A$. perspicuus (4). F irst instar nymph, (5). Second instar nymph, (6). Third instar nymph

Third instar nymph (Tables 1 and 2, Figs. 3 and 6): In general characters it resembles the second instar nymph and measures $1.90 \mathrm{~mm}$ in length and $1.1 \mathrm{~mm}$ in breadth. Pigmentation increases in the head and thorax is now clearly evident in the abdomen. The chaetotaxy of the nymph shows an increase (Figs. 3 and 6)

The head has become triangular in shape the mandible darker and prominent. The hypopharynx and gular plate are well differentiated. The prothorax remains the same in shape and chaetotaxy, but the pterothorax shows further increase in the concavity of its posterior margin and in the number of setae. The articulating sclerites of the first and second pairs of legs become darker and harder.

The abdomen has become elliptical and dark brown areas 
have appeared on the dorsal side along the lateral margin of segments II - IV. Segmentation is clearly visible. Segments IX and $\mathrm{X}$ is now completely fused as the suture present in the second instar nymph has disappeared (Fig. 3 ). The chaetotaxy and body measurements of third instar nymph are given in Table 1 and 2.

\section{DISCUSSION}

Survey of literature reveals that three nymphal instars of avian lice differ mainly in the dimension of body parts and number of setae (Clay, 1958; Lonc and Modrejewska 1986 and 1989; Page et al., 1995; Saxena et al., 1998; Smith, 2000; Cicchino and Castro, 2002 and Silke, 2006; Modrejewska and Zlotorzycka, 1987). In few species the nymphal instars can be identified by the modification of setae. Gradual appearance of new setae and darkening of sclerites in nymphs have been noted by the workers. The diagnosis of nymphal instar through the progression of chaetotaxy has been recommended by Clay (1958). The second instar nymph of $A$. perspicuus can be differentiated from first instar on the basis of nature of head (lateral margins straighter, hypopharynx darker and discernible gular plate), thorax (posterior margins more concave), segmentation of abdomen (which is more clearer and a faint suture appears between segment IX and $\mathrm{X}$ ) and increased number of tergal, sternal and pleural setae. Likewise, the third instar nymph of A. perspicuus can be separated from second instar on account of nature of head (more triangular, prominent mandibles, well differentiated gular plate and hypopharynx), prothorax (increased concavity of posterior margin), abdominal segmentation (segment IX and X fused) and increased number of tergal, sternal and pleural setae.

\section{ACKNOWLEDGMENTS}

The authors are thankful to the Principal, Govt. Raza P. G. College, Rampur for providing laboratory facilities.

\section{REFERENCES}

Cicchino, A.C. and Castro, D. C. (2002). Nymphal stages of Abrocomophaga hellenthali (Phthiraptera: Gyropidae), a parasite of 0 ctodon degus (Rodentia, Octodontidae).
Iheringia, Serie Zoologia Porto Alegre, 92(4): 19-24.

Clay, T. (1958). Revisions of Mallophaga genera D egeer iella from the Falconiformes. Bulletin of B ritish M useum Natural History on Entomology (London), 7: 123-207.

Lonc, E. and Modrezejewska, M. (1986). An attempt to identification of nymphal instars of bitting lice (Mallophaga) using discriminent fuction. Bulletin entomologique de pologme. Tom, 56:631-640.

Lonc, E. and Modrezejewska, M. (1989). Growth rules applied to the stage identification of nymphal instars of some mallophogan species (Phthiraptera). D eutsch Entomology, 36:121-126.

Mey, E. (1994). Beziehungen Zwischen larvemorphologie und systematik der adulti bei den vogel-Ischnozeren (Insecta, Phthiraptera, Ischnocera). Mitteilungen aus dem Zoologischen M useum, Berlin, 70: 3-84.

Modrzejewska, M. and Złotorzycka, J. (1987). Studies on morphology of nymphs of selected Amblycera and Ischnocera (Mallophaga). Polskie Pismo Entomologiczne, 57:657-672.

Page, R. D. M., Price, R.D. and Hallenthal, R.A. (1995). Phylogeny of Geomydoecus and Thomodoecus pocket gopher lice (Phthiraptera : Trichodectidae) inferred from cladistic analysis of adult first instar morphology. Systematic Entomology, 20: 129-143.

Price, R. D. and Hellenthal, R. A. (1996). Taxonomic importance of first instar chewing lice (Phthiraptera: Philoterpidae) from neotropical antbirds and Giant eaters (Aves: Passeriformes). J ournal of Kansas Entomological Society, 69: 346-356.

Saxena, A. K., Surman, Singh, S. K. and Kumar, A. (1998). Description of life history stages of poultry shaft louse, Menopon gallinae (Phthiraptera: Amblycera, Menoponidae). Rudolstadter naturhistorischce Schriften, 9: 81-85.

Saxena, A. K., Singh, S.K., Surman, Kumar, A. and Badola, S. (2000). SEM studies on the microtopography of eggs of four pigeon lice (Phthiraptera, Insecta). Rivista di Parasitologia, XVII (LX1) N3: 351-358.

Silke, K., Michael, O. and Ragnar, K. (2006). Identification of larval instars of the Phthiraptera Ectoparasite Campanul otes bidentatus compar. (Burmeister, 1838) by the setal patterns. Deutsch entomology Z, 53: 86-90.

Smith, V.S. (2000). Basal ischnoceran louse phylogeny (Phthiraptera: Ischnocera: Goniodidae and Heptapsogasteridae). Systematic Entomology, 25: 73-94. 